\title{
A comparative pressure analysis of air flow between horizontal and V-Tail of UAV MALE of NACA0012H with speed variation
}

\author{
Rahmat Riza ${ }^{*}$, Dicky Kurniawan, and Arif Budi Wicaksono \\ Universitas Islam Indonesia, Yogyakarta, Indonesia
}

\begin{abstract}
NACA0012H is an airfoil type that could be used for Unmanned Aerial Vehicle Medium Altitude Long Endurance. This experiment was used to analyze stress in the surface of Tail of UAV MALE that was caused by air flow. The experiment was conducted using Computational Fluid Dynamics Software. Two designs of tail, horizontal and $V$-tail, were considered to simulate pressure occurred on the surface of leading edge, chamber and trailing edge. The simulation was developed varying the speed of the UAV MALE. The results showed that pressure occurred on the surface of horizontal tail higher than pressure on the $V$-tail.
\end{abstract}

\section{Introduction}

Unmanned Aerial Vehicles (UAV) simply could categorize as plane which remotely control outside of its plane [1]. Hence, the design of UAV would be identic with the actual aircraft where the ability of UAV to fly determined by the design of its aerofoil. This could be understood that the effectivity of the wing of the aircraft or UAV to produce aerodynamic force was determined by the design of air foil [2]. This force is important to obtain optimum process for the aircraft to fly in the air. The aerofoil referred to the profile of the wings of the aircraft which obtain by cutting section that was perpendicular to the wing [3]. Therefore, tail or empennage on a UAV plane has the same function as a full-scale aircraft, which is to provide both longitudinal (pitch) and directional stability (yaw).

The selection of tail geometries is based on mission requirements, as the example for take-off and landing conditions, manoeuvres, payload laying, propeller configurations, drive systems (servo) to aesthetic aspects. The tail design should consider the lightest and strongest material and construction and not disturbance the engine exhaust. The tail could be designed as small as possible to obtain minimum weight.

One variation of the tail has $V$-shape, known as $V$-Tail. This is generated combining the vertical fin and stabilizer into a pair of controls. The theoretical advantage of this design is lighter than $T$-tail and to reduce the interference drag associated with two surfaces [1]. This could be established by simulating the pressure resulted in the design. Computational Fluid Dynamic (CFD) could be used to simulate the pressure change especially in the change of the speed of air flow in the tail itself.

In this study, NACA0012H was applied to construct aerofoil profile in order to explore the pressure change of horizontal and $V$-tail design. This was caused that air foil design from NACA widely used in the aerofoil design for aircraft or UAV [3], especially for NACA0012 [4, 5].

\section{Simulation Methods}

In this work, two design of tails, horizontal and $V$-tails, were simulated using CFD software to analyse the change of its pressure resulted by variation of air flow through it surface. The model simulation was conducted to investigate the change of the pressure in three important region of the tail for both designs. The important areas of the tail are given on Fig.1 [3, 6].

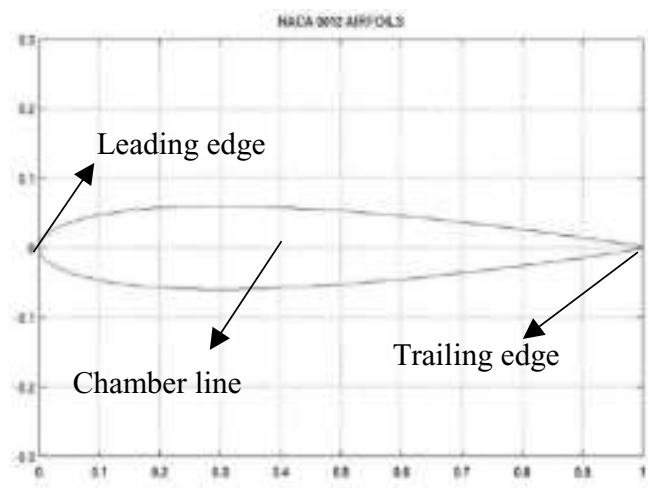

Fig 1. The geometry aerofoil of NACA 0012

Pressure which acted in all of the areas had been established as variation speed of the aircraft or UAV. The design of the tail was expected to reach speed of $240 \mathrm{~km} / \mathrm{h}$ and to carry in till $400 \mathrm{~kg}$ payload. This could be categorized as UAV with specification for Medium Altitude Long Endurance (MALE). Four speed variations were selected in order to simulate the change of pressure in the important region of the tail, namely $165 \mathrm{~km} / \mathrm{h}, 195$ $\mathrm{km} / \mathrm{h}, 210 \mathrm{~km} / \mathrm{h}$ and $240 \mathrm{~km} / \mathrm{h}$. The results were used to analyse the advantages of either horizontal or $V$-tail.

\footnotetext{
* Corresponding author: rahmatriza@uii.ac.id
} 


\section{Results and Analysis}

The accomplished CFD simulation had generated two results which would be analysed in this paper. The first result was a general description of the pressure acting in tail of UAV MALE in horizontal and $V$-tail design. This result would be discussed in Section 3.1 for the horizontal tail and Section 3.2 for the $V$-tail design. The second result was the pressure variation in the three specific region of tail either in the horizontal and $V$-tail design. This result would be discussed in Section 3.3.

\subsection{Simulation Results on Horizontal Tail UAV MALE}

The simulation of air flow in the area of the horizontal tail was conducted in the seven variation speed, namely 150 $\mathrm{km} / \mathrm{h}, 165 \mathrm{~km} / \mathrm{h}, 195 \mathrm{~km} / \mathrm{h}, 210 \mathrm{~km} / \mathrm{h}, 240 \mathrm{~km} / \mathrm{h}$. The overall results are given in Table 1 .

Table 1. Simulation results for pressure of the horizontal tail

\begin{tabular}{|c|c|c|c|}
\hline \multirow{2}{*}{$\begin{array}{c}\text { Velocity } \\
(\text { Km/h) }\end{array}$} & \multicolumn{2}{|c|}{ Pressure (Pa) } & \multirow{2}{*}{$\begin{array}{c}\text { Pressure } \\
\text { Range (Pa) }\end{array}$} \\
\cline { 2 - 3 } & Maximum & Minimum & \\
\hline 150 & 113815.75 & 93627.89 & 20187.86 \\
\hline 165 & 116595.62 & 92041.64 & 24553.98 \\
\hline 180 & 120745.51 & 89587.19 & 31158.32 \\
\hline 195 & 124566.19 & 87941.76 & 36624.43 \\
\hline 210 & 128310.97 & 85795.96 & 42515.05 \\
\hline 225 & 132404.45 & 82952.14 & 49452.31 \\
\hline 240 & 136866.99 & 79445.62 & 57421.37 \\
\hline
\end{tabular}

Table 1 showed the simulation results for every speed variation. The values of Table 1 showed that the increase of aircraft speed had resulted parallel value with the increase of the maximum pressure. In other hand, the increase of aircraft speed looked contrary with minimum pressure value acting on the surface of the tail. This data showed that the effect of the increase of the speed had different impact between the maximum and minimum working pressure.

The entire acting pressure on the surface of the tail is given in Fig. 2 and Fig. 3. Fig. 2 showed the simulation results for the pressure acting on the surface of the tail with the speed of $165 \mathrm{~km} / \mathrm{h}$ where Fig. 3 referred to the simulation for speed of $210 \mathrm{~km} / \mathrm{h}$.

Fig. 2 and Fig. 3 show pressure variation acting in the horizontal tail. This result was generated from the pressure acting caused by air flow with assumption that the tail is in the speed of $165 \mathrm{~km} / \mathrm{h}$ and $210 \mathrm{~km} / \mathrm{h}$. Based on the legend, we could conclude that the tail had the highest pressure in the front side of the tail. They were concentrated in some points. Simulation results for variation speed of $165 \mathrm{~km} / \mathrm{h}$ and $210 \mathrm{~km} / \mathrm{h}$ overall had similar region of the pressure acting on the surface of the tail. However, simulation results for the speed of 210 $\mathrm{km} / \mathrm{h}$ had generated lower pressure in the region which the minimum pressure act.

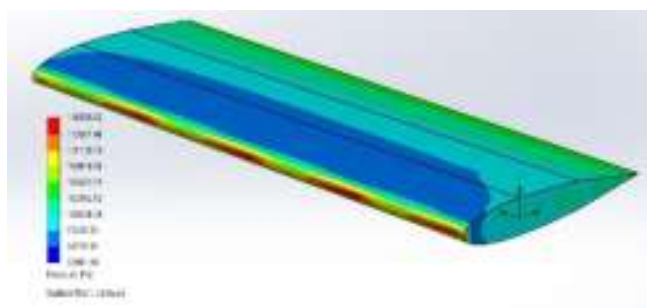

Fig 2. Pressure Surface Aerofoil with speed of $165 \mathrm{~km} / \mathrm{h}$

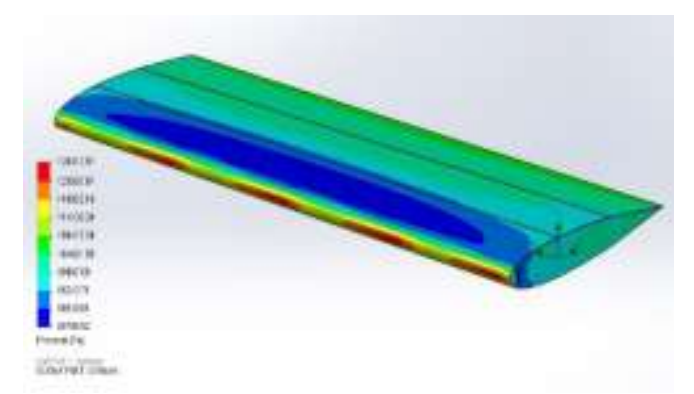

Fig 3. Pressure Surface Aerofoil with speed of $210 \mathrm{~km} / \mathrm{h}$

However, the pressure caused by the air flow acted in the end of the tail not too much different compare to the pressure acting in the front side. The area of the tail had received the lowest pressure located near to the area that had the highest pressure. This could be ensued due to the pressure of the air flow highly concentrate in some points.

The flow of the air through the tail are given in Fig. 3.

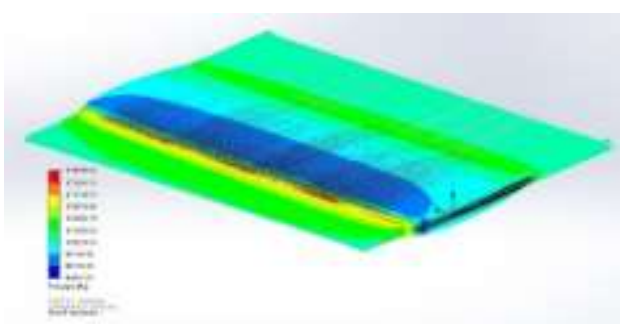

Fig 4. Flow Pressure Surface Aerofoil with speed of $165 \mathrm{~km} / \mathrm{h}$

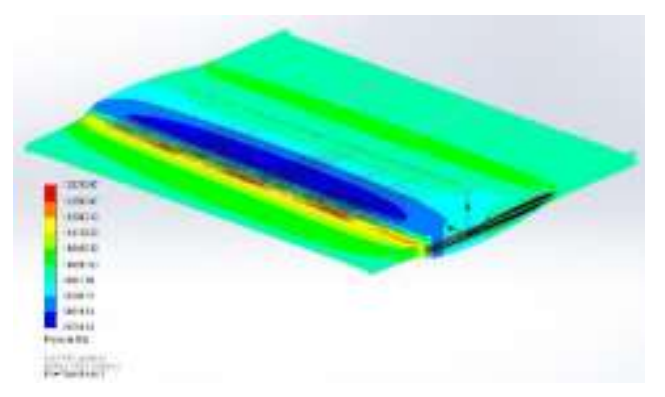

Fig 5. Flow Pressure Surface Aerofoil with speed of $210 \mathrm{~km} / \mathrm{h}$

In Fig. 4 and Fig. 5, the air flow was overall described. This results also showed where the area of air around the 
tail effected by the acting pressure on the surface of the tail caused by the speed of the aircraft. Those, However, the pressure caused by the air flow acted in the end of the tail not too much different compare to the pressure acting in the front side. The area of the tail had received the lowest pressure located near to the area that had the highest pressure. This could be ensued due to the pressure of the air flow highly concentrate in some points.

The samples contour of aerofoil are given in Fig. 6 for speed of $165 \mathrm{~km} / \mathrm{h}$ and Fig. 7 for speed of $210 \mathrm{~km} / \mathrm{h}$. The pattern drawn of both simulations had quite different especially in low pressure. There is change the area of light blue pattern and the both area of green pattern. This showed the increase of pressure that was parallel with the increase the speed of the tail.

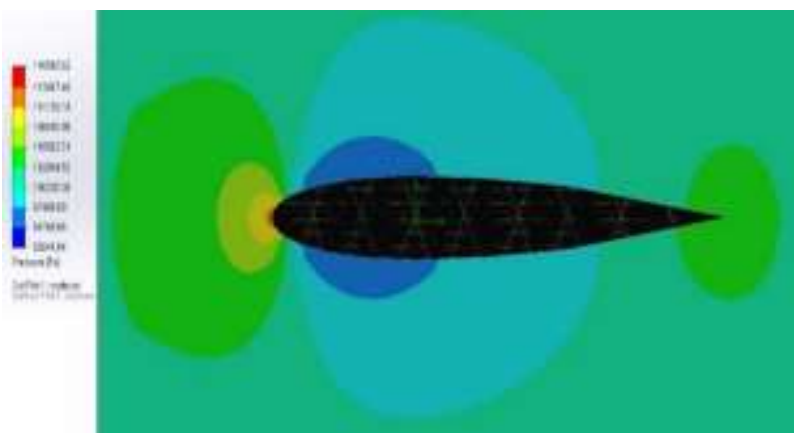

Fig 6. Contour Pressure Surface Aerofoil with speed of 165 $\mathrm{km} / \mathrm{h}$

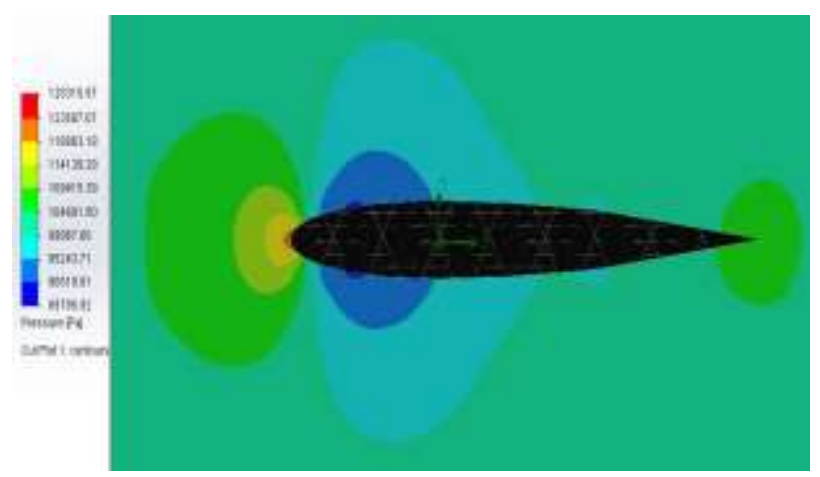

Fig 7. Contour Pressure Surface Aerofoil with speed of 210 $\mathrm{km} / \mathrm{h}$

The other area of the tail had received the pressure evenly distributed. This was shown by the area of each colour pattern. The results of both speed variations in this pressure range had been drawn within similar pattern.

\subsection{Simulation results on $V$-tail UAV MALE}

Besides the horizontal design, the tail of UAV had been proposed using $V$-shape or $V$-configuration [Babbu..]. Therefore, the analysis of NACA00012 aerofoil had been simulated in the $V$-configuration in this experiment. The overall results $V$-tail are given on Table 2 .

The simulation results of the $V$-tail as given on the Table 2 showed the similar pattern as the results of the horizontal tail. The increase of the aircraft speed is in line with the increase of maximum pressure and the range pressure acting on the tail. However, this ensued till the speed $210 \mathrm{~km} / \mathrm{h}$. After this speed, there is a reduction of the maximum pressure acting on the aerofoil. The maximum pressure looked decreasing while the speed of aircraft rising from $210 \mathrm{~km} / \mathrm{h}$ to $240 \mathrm{~km} / \mathrm{h}$. The increase speed, in fact, had caused the reduction of the minimum pressure acting on the aerofoil in this configuration.

Table 2. Simulation results for pressure of the $V$-tail

\begin{tabular}{|c|c|c|c|}
\hline \multirow{2}{*}{$\begin{array}{c}\text { Velocity } \\
(\mathbf{K m} / \mathbf{h})\end{array}$} & \multicolumn{2}{|c|}{ Pressure (Pa) } & \multirow{2}{*}{$\begin{array}{c}\text { Pressure } \\
\text { Range (Pa) }\end{array}$} \\
\cline { 2 - 3 } & Maximum & Minimum & 41088.36 \\
\hline 150 & 132984.51 & 91896.15 & 87084.11 \\
\hline 165 & 170740.01 & 83655.90 & 83088.15 \\
\hline 180 & 162794.92 & 79706.77 & 113161.33 \\
\hline 195 & 188658.64 & 75497.31 & 132942.32 \\
\hline 210 & 211780.13 & 78837.81 & 109071.47 \\
\hline 225 & 187643.06 & 78571.59 & 114652.28 \\
\hline 240 & 186030.17 & 71377.89 & \\
\hline
\end{tabular}

Description of the working pressure on the tail with specific speed had been simulated as shown on Fig. 8 and Fig.9. Fig. 8 refers to the simulation results for the pressure action on the tail at speed $165 \mathrm{~km} / \mathrm{h}$ while Fig. 9 refers to the speed of $210 \mathrm{~km} / \mathrm{s}$. The pattern resulted from the CFD simulation for both speed variations looked significantly different.

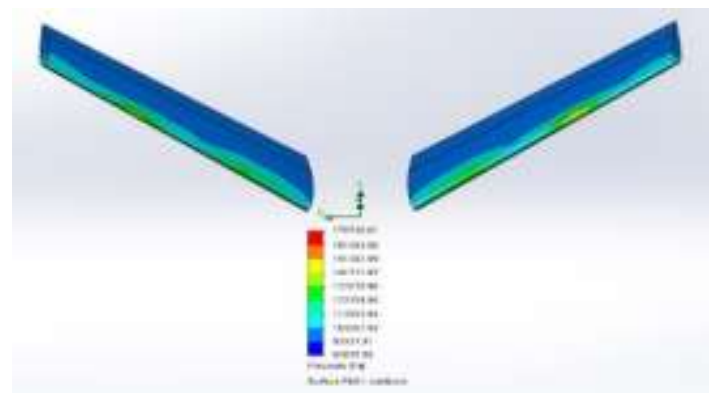

Fig 8. Pressure Surface Aerofoil with speed of $165 \mathrm{~km} / \mathrm{h}$

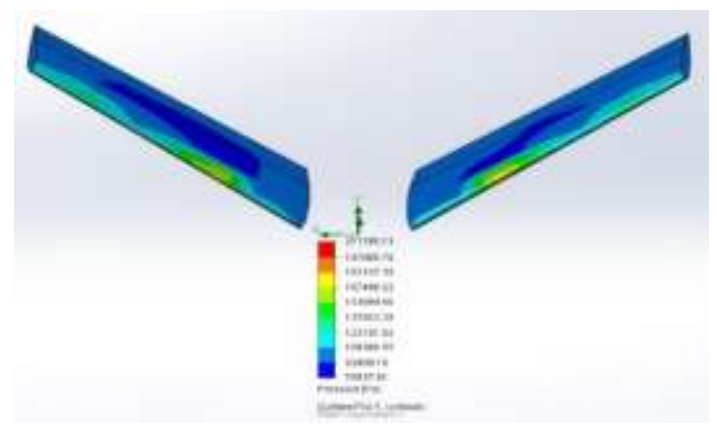

Fig 9. Pressure Surface Aerofoil with speed of $210 \mathrm{~km} / \mathrm{h}$

The pattern of simulation results for the speed of 210 $\mathrm{km} / \mathrm{h}$ had dark blue colour. This colour refers to the lowest pressure acting on the tail. This is not found in the result for speed variation of $165 \mathrm{~km} / \mathrm{h}$. The maximum pressure working on the tail also had few desperate in the simulation results as described in Fig. 8 and Fig. 9. The speed variation of $210 \mathrm{~km} / \mathrm{h}$ had yellow colour. This colour is pointing to the highest value of the pattern in 
both Fig. 8 and Fig. 9. This is consistent with the results given on the Table 2 .

The description of the value of Table 2 was able to be illustrated with the comparison of the air flow pressure between specific speed value. In this case, simulation results for the speed of $165 \mathrm{~km} / \mathrm{h}$ and $210 \mathrm{~km} / \mathrm{h}$ were selected to compare the pattern. This is given on Fig.10 and Fig.11. Both figures visualized the results of lower speed and higher speed. Fig. 10 illustrated the working pressure of the air flow within speed of $165 \mathrm{~km} / \mathrm{h}$ while Fig. 11 represented the pressure in the speed of $210 \mathrm{~km} / \mathrm{h}$.

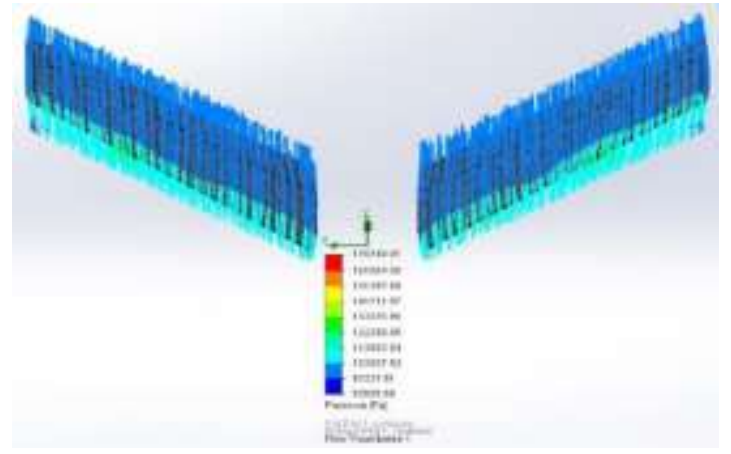

Fig 10. Flow Pressure Surface Aerofoil with speed of $165 \mathrm{~km} / \mathrm{h}$

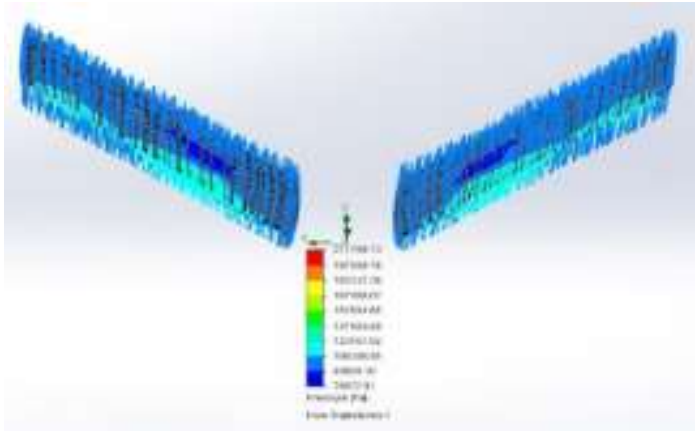

Fig 11. Flow Pressure Surface Aerofoil with speed of $210 \mathrm{~km} / \mathrm{h}$

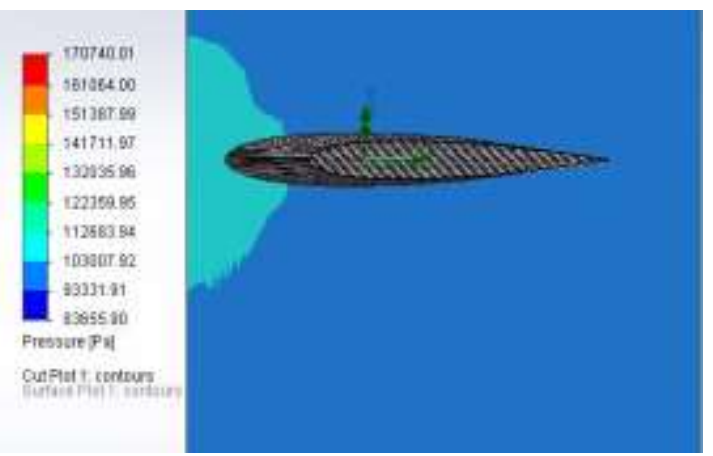

Fig 12. Contour Pressure Surface Aerofoil with speed of 165 $\mathrm{km} / \mathrm{h}$

At a glance, the pattern of flow pressure surface aerofoil with speed of $210 \mathrm{~km} / \mathrm{h}$ is more complicated compare than the pattern for the speed of $165 \mathrm{~km} / \mathrm{h}$. This was supported by the contour pressure surface simulated by CFD as given on Fig. 12 and Fig. 13. Fig. 12 represent the contour pressure surface produced by air flow with speed of $165 \mathrm{~km} / \mathrm{h}$ and Fig. 13 as the result of speed of $210 \mathrm{~km} / \mathrm{h}$.
The contour effected by air flow with speed of 210 $\mathrm{km} / \mathrm{h}$ had more pattern compared than the area generated by air flow with speed of $165 \mathrm{~km} / \mathrm{h}$. This means that the pressure generated by air flow with speed of $210 \mathrm{had}$ higher pressure range than air flow with speed of 165 $\mathrm{km} / \mathrm{h}$. The results at speed of $210 \mathrm{~km}$ had area with dark blue colour which is refer to the lowest pressure among the pattern in the Fig. 12 and Fig. 13.

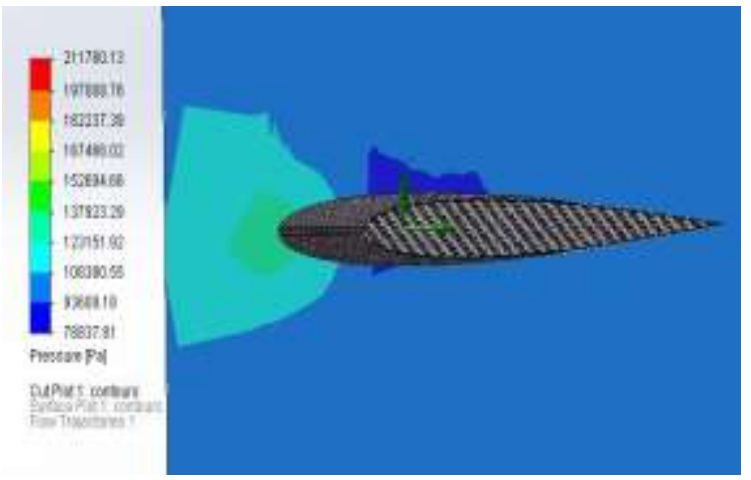

Fig 13. Contour Pressure Surface Aerofoil with speed of 210 $\mathrm{km} / \mathrm{h}$

At a glance, the pattern of flow pressure surface aerofoil with speed of $210 \mathrm{~km} / \mathrm{h}$ is more complicated compare than the pattern for the speed of $165 \mathrm{~km} / \mathrm{h}$. This was supported by the contour pressure surface simulated by CFD as given on Fig. 12 and Fig. 13. Fig. 12 represent the contour pressure surface produced by air flow with speed of $165 \mathrm{~km} / \mathrm{h}$ and Fig. 13 as the result of speed of $210 \mathrm{~km} / \mathrm{h}$.

\subsection{Pressure comparison of the tail}

The simulation had also performed to analyse pressure acting in the three important area of the tail. This will be discussed in the form of comparison among the horizontal and $V$-tail.

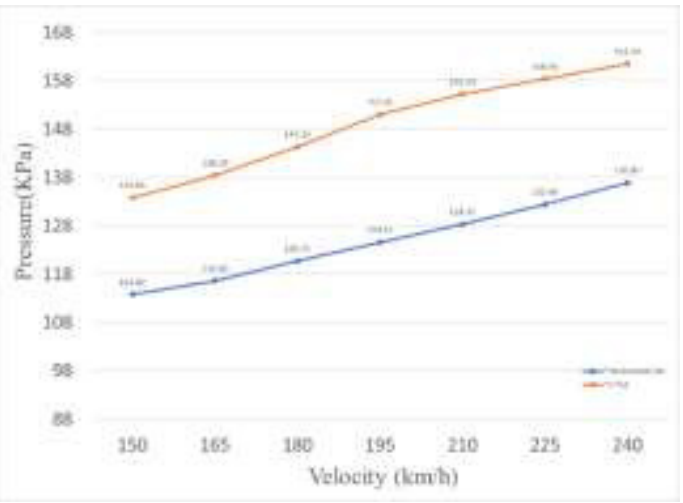

Fig 14. Pressure comparison in the area of maximum Leading Edge

\subsubsection{Pressure comparison on the Leading Edge}

Based on the computer simulation, the pressure values on the horizontal and the $V$-Tail in the area of Leading Edge are presented in graphical format shown in Fig. 14 and Fig. 15. 


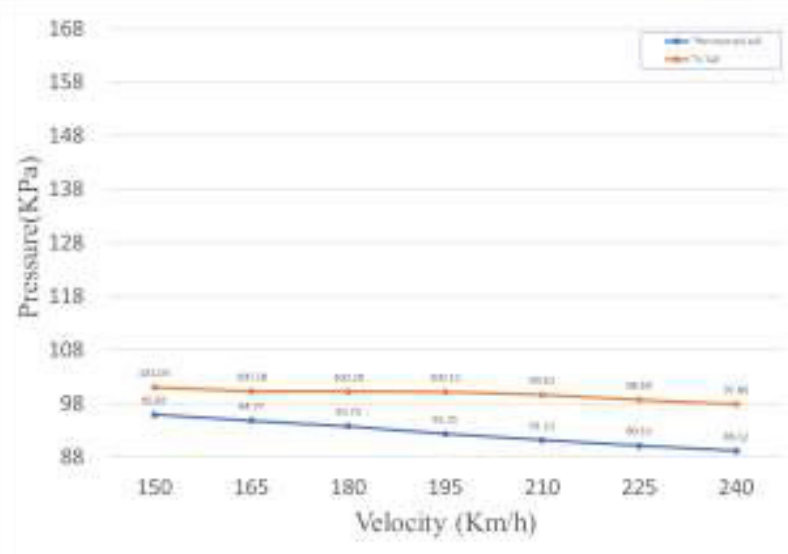

Fig 15. Pressure comparison in the area of minimum Leading Edge

Fig. 14 and Fig. 15 has shown the comparative graph of the pressure values occurring in the Leading Edge region of each wing model. Both graphs shown a relatively similar pattern. It appears that the maximum and minimum pressure values occurring on the V-Tail wing model are larger than the horizontal wing model. The pattern for the maximum leading edge region looked to have a tendency to decrease with the increasing speed of UAV MALE. In the other side, the trend of the minimum leading edge is in contrary tendency.

\subsubsection{Pressure comparison on the Chamber}

Results of computer simulation on the chamber area are given on Fig. 16 and Fig. 17.

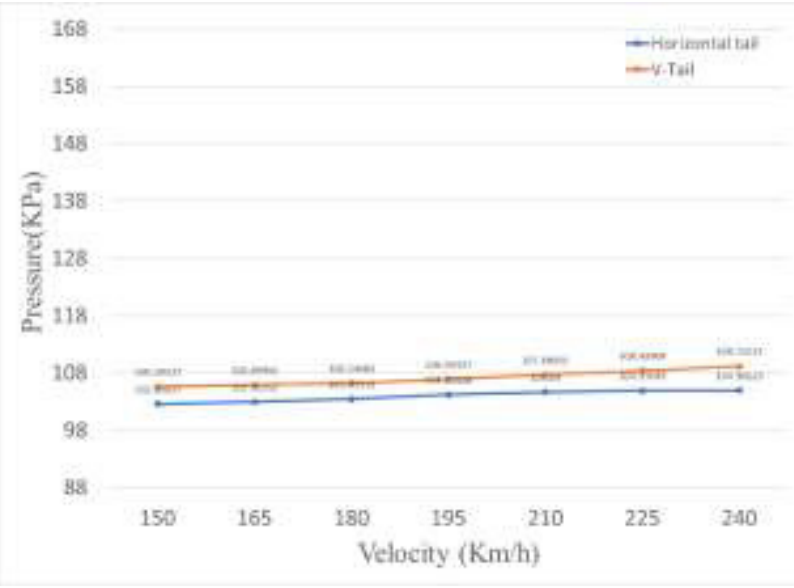

Fig 16. Pressure comparison in the area of maximum Chamber

Where Fig. 16 shows the pressure occurred in the maximum chamber region and Fig. 17 refers to the minimum chamber region. The trend of the pressure change for both horizontal and $V$-tail have similar tendency in the region of the maximum and minimum chamber. However, the pressure trend in the maximum chamber area has downward inclination. This is different with the pressure trend in the minimum chamber region.

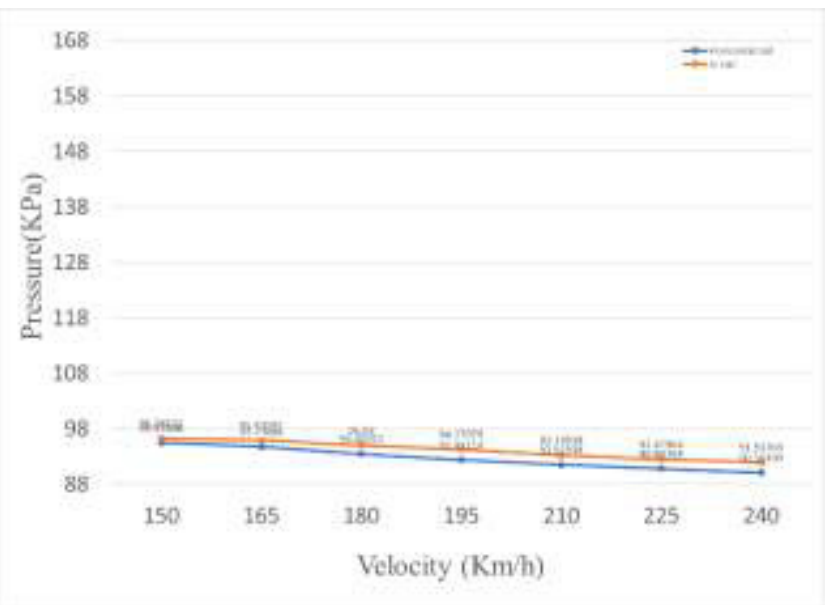

Fig 17. Pressure comparison in the area of minimum Chamber

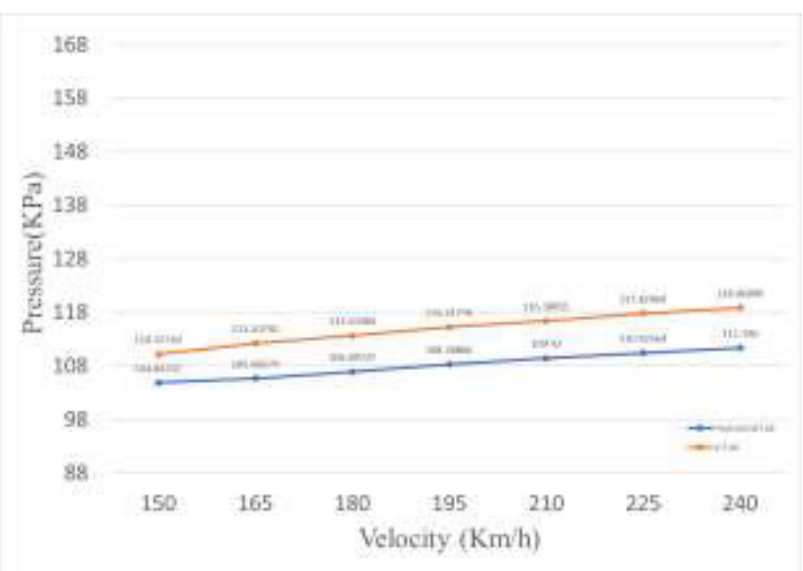

Fig 18. Pressure comparison in the area of maximum Trailing Edge

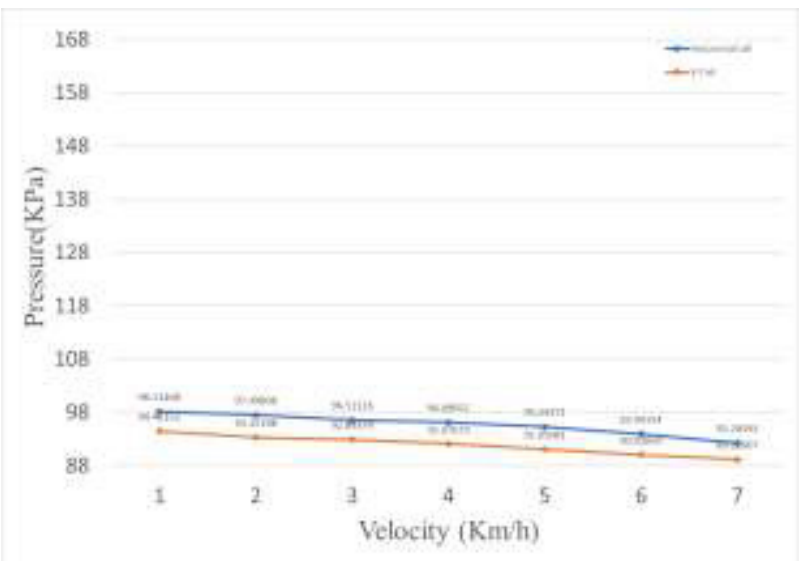

Fig. 19 Pressure comparison in the area of minimum Trailing Edge

\subsubsection{Pressure comparison on the Trailing Edge}

Results of the computer simulation on the trailing edge are given on Fig. 18 and Fig. 19.

In the region of trailing edge, the simulation results also demonstrated the adverse profile between maximum and minimum region of the trailing edge. This is in line 
with the illustration given by the value of Table 1 and Table 2.

\section{Conclusion}

From the CFD simulation results, it can be seen that the maximum pressure arising from the air flow rate is directly proportional to the speed. The faster the speed of the plane, the resulting pressure is also greater, however, the minimum pressure had a contrast condition for both horizontal and V-tail. This condition could also found in the specific geometry for both horizontal and V-tail.

Furthermore, the pressure range will be greater if the rate of aircraft getting faster for both horizontal and $\mathrm{V}$ tail. The pressure range of $\mathrm{V}$-tail was higher than range for the horizontal tail. The highest range occurred in the V-tail with value of $114652,28 \mathrm{~Pa}$. This condition had taken place caused by the minimum pressure acting in aerofoil is hand in hand with its maximum values. However, the highest pressure acting still on the horizontal tail namely the working pressure in the speed of $210 \mathrm{~km} / \mathrm{h}$ with value of $136866.99 \mathrm{~Pa}$.

The author would like to thank to Mechanical Engineering Department to fully support for this work and all the people involved in this work.

\section{References}

1. Babu, P. Hussain, Rodriguez Arthurs S.A, S. Mahaboob Basha, Sadiq. P., Design and Analysis of $V$-Tail Unmanned Air Vehicle (UAV) for Surveillance Application, International Journal of Engineering Trends and Technology (IJETT), 32, Number 3 (2016)
2. Azeez VP, Abdul, John Paul CFD Analysis of NACA 63-018 Airfoil at Different Reynolds-Number, International Journal of Engineering Trends and Technology (IJETT), 12, No. 5 (2014)

3. Mustak, Rubiat, Md. Habib Ullah Khan, Md. HarunOr-Rashid Molla, Design and Construction of NACA4415 Airfoil with Various Shaped Surface Modification, Asia Pacific Journal of Engineering Science and Technology, 3, No. 1, PP. 28-38 (2017)

4. Garg, Pankaj, Neelesh Soni, Aerodynamic Investigation of Flow Parameter over NACA 4415 Airfoil by Computational Fluid Dynamics, International Journal of Recent Scientific Research, 7, Issue 5, PP. 10737-10741, (2016)

5. Ahmadi-Baloutaki, Mojtaba, Ahmad Sedaghat, Mohsen Saghafian, Mohammad Ali Badri, A computational study on robust prediction of transition point over NACA0012 aerofoil surface from laminar to turbulent flows, Theoretical \& Applied Mechanics Letter, 3, 042004 (2013)

6. Ahmed, Tousif, Md. Tanjin Amin, S.M. Rafiul Islam, Shabbir Ahmed, Computational study of flow around a NACA 0012 wing flapped at different flap angles with varying mach numbers, 13, 4 (2013) 